\title{
How can visualisation principles be used to support knowledge transfer in teaching and learning?
}

\author{
Olakumbi A. Fadiran \\ School of Computing \\ University of South Africa \\ olakumbi@gmail.com
}

\author{
Judy van Biljon \\ School of Computing \\ University of South Africa \\ Vbiljja@unisa.ac.za
}

\author{
Marthie A. Schoeman \\ School of Computing \\ University of South Africa \\ Schoema@unisa.ac.za
}

\begin{abstract}
Visualisation has proven benefits in supporting knowledge transfer. Furthermore, it can enable learners to become co-creators rather than only consumers of knowledge. Technological advancements have made visualisation more accessible as a mechanism to improve teaching and learning but theorisation and best practices are lacking. This study aims to investigate the usefulness of knowledge visualisation principles for improving knowledge presentation and demonstrating knowledge transfer by high school learners. A design-based research methodology is applied which required the creation and evaluation of guidelines (artefacts) in order to assess the effects of knowledge visualisation principles while visualising. The results indicate that some of the knowledge visualisation principles extracted from literature could improve knowledge transfer in secondary school education. The contribution of this paper is to propose a set of validated knowledge visualisation guidelines towards the theory and practice of using knowledge visualisation in teaching and learning.
\end{abstract}

Keywords- Knowledge visualisation, knowledge visualisation principles

\subsection{Introduction}

Modern technology opened many possibilities to using visualisation for educational purposes. An important role of a teacher is to aid the transfer of knowledge to students in a way that is meaningful and understandable [1]. The teacher uses his/her expertise to select and use teaching materials such as textbooks, lecture notes, multimedia resources etc. to assist in this role [2]. Teachers also employ specific strategies to support knowledge creation and transfer, and one of such strategies is visualisation [3]. Visualisation entails using images to communicate data, however, teachers, educational, learning and instructional designers are often the ones creating these visual images for teaching and learning [4] with little or no input from learners. According to [5], learners should be cocreators of their learning experience rather than having knowledge merely made available for learners' consumption.

For the scope of this research, the focus will be on the usefulness of knowledge visualisation principles for secondary school learners to construct, demonstrate and internalise the new knowledge that they are expected to master. The ability of learners to acquire, assimilate and sort knowledge plays an important role in their learning process as learners are unique in the manner they absorb, process and store information. To internalise knowledge, learners have to engage in its creation [5].

2017 Conference on Information Communications Technology and Society, ISBN 978-1-4673-8996-9
To explore how knowledge visualisation principles can be used for improving knowledge presentation and transfer by high school learners in a way that the teacher can assess the student's understanding, a group of high school learners were asked to create visualisation models to explain the process of a rocket launch. Learners were then exposed to knowledge visualisation principles and the initial images produced were updated to accommodate these principles. The goal of the exercise was to investigate the effect of each principle on the images produced by the learners and how the principles have helped improve their knowledge representation towards demonstrating their knowledge acquisition.

The rest of the paper gives a brief insight to what knowledge visualization entails and the degree of compliancy by learners on knowledge visualization guidelines. This is useful in selecting and prioritising knowledge visualisation principles for this group.

\subsection{Literature review}

Manovich [6] defined visualisation as the conversion of measurable data into a visual representation. Visualisation is further explained as the use of images to represent spatial and non-spatial variables in a manner that reveals its patterns and relations [6-8].

\subsection{What is knowledge visualisation?}

Knowledge visualisation according to [9] is the act of representing complex concepts and data using graphics and animations in ways that people have not seen before, in order to aid knowledge transfer and creation. Zhang et al. [1] and Burkhard [10] explained knowledge visualisation as the act of exploring the use of visual representations such as graphs, diagrams, drawings, sonographs etc. to enhance knowledge creation and transfer between at least two people. For [11], it is a process that entails various steps such as gathering, interpreting, developing, understanding, designing and sharing information. Eppler [12] relates the term to the use of graphics to create, integrate and administer knowledge. Van Biljon \& Renaud [13] noted that the primary aim of knowledge visualisation is knowledge transfer whereas that of information visualisation is to support pattern identification. In summary, knowledge visualisation entails the creation of knowledge, using available visual resources in a manner that is understandable and communicable to other people. 


\subsection{Knowledge visualisation principles}

A systematic literature review (SLR) process was used to gather design guidelines from the field of information and knowledge visualisation. The SLR was selected as a protocol that is claimed to be replicable, transparent, objective, unbiased and rigorous [14-16]. The databases used are IEEE Xplore, Google Scholar, Scopus, Springer and ACM, and the search strings used are those that returned results containing at least one of the terms knowledge/information

knowledge/information visualisation

visualisation, principles, conducted between February and October 2017 for English papers published in conferences and journals.

Table 1 is a matrix table that gives a summary of knowledge visualisation principles from literature that can be used to improve images produced for knowledge representations.

Table 1: Knowledge visualisation principles from literature

\begin{tabular}{|c|c|c|}
\hline Knowledge visualisation guidelines & Description & Author(s) \\
\hline Abstract (compress) the knowledge & Extracting essential components and their relationships from a body of knowledge. & {$[17-21]$} \\
\hline Present overview and details & $\begin{array}{l}\text { 'overview' gives a context information of the field while the 'detail' gives more information } \\
\text { about a part of the overview. }\end{array}$ & {$[20,23,24]$} \\
\hline Consistency & $\begin{array}{l}\text { The use of visual elements such as colour, symbols, shapes etc. should be the same for the } \\
\text { same kinds of information. }\end{array}$ & {$[24,25]$} \\
\hline Easy to understand & $\begin{array}{l}\text { Presenting visualisation in a clear, comprehensive way makes it easy to understand, such that } \\
\text { little previous knowledge of the content is required. }\end{array}$ & {$[26,27]$} \\
\hline Know your data & $\begin{array}{l}\text { A designer must first understand and explore the data domain in order to create images that } \\
\text { are meaningful and relevant. }\end{array}$ & {$[24,26]$} \\
\hline Clarity & The use of defined symbols to avoid ambiguity. & {$[25,28]$} \\
\hline Know your audience & $\begin{array}{l}\text { The designer should consider for whom the visualisation is intended e.g. an individual, a } \\
\text { group, a network etc. }\end{array}$ & {$[29]$} \\
\hline Use natural representations & $\begin{array}{l}\text { Associating visualisation with real world allows a recognition-based approach to interpreting } \\
\text { images instead of one that requires recall. }\end{array}$ & {$[30-33]$} \\
\hline Legend & $\begin{array}{l}\text { An accompanying item which: provides detailed explanations on symbols used, can become } \\
\text { a control panel for making changes and provide multiple views onto data. }\end{array}$ & {$[20,34]$} \\
\hline Use of colours & $\begin{array}{l}\text { To: specify a format that is applicable to a set of instances, differentiate relationships, } \\
\text { beautification, grouping, mapping and classifying images. }\end{array}$ & {$[18,24,35,36]$} \\
\hline Avoid decorations & The use of irrelevant elements may distract the audience from the content of the topic & {$[25,32]$} \\
\hline Relationship between concepts clearly shown & Relationship between concepts can be illustrated using links & {$[28,38]$} \\
\hline Motivate audience & To enhance learning engagement & {$[39,9]$} \\
\hline Simplicity & Minimizing the number of concepts in each level of visualisation to $7 \pm 2$ objects . & {$[28]$} \\
\hline Dual coding & Using both textual and visual representation to process information. & {$[40-42]$} \\
\hline Clear boundaries & To help with navigation and enclosing knowledge within a specific domain. & [43] \\
\hline
\end{tabular}

\subsection{Research methodology}

A design-based research methodology was applied to this study as it identifies with real world situations [44]. To create the knowledge visualisation models (artefacts) for the designbased research, a research group comprising high school learners and teacher was created and structured as a way to gather information about the impact of knowledge visualisation principles for supporting knowledge transfer. The method was used because it facilitated interaction between teacher and learners and enabled us to obtain qualitative and quantitative information from participants easily.

\subsection{Procedure}

The study was conducted at the Rooihuiskraal Library, Pretoria and participants were provided with computers with internet connection. There was a total of 22 participants (19 learners, 1 educator, 1 usability tester and 1 researcher). The 19 learners ( 6 females) are high school learners randomly selected from various schools in Pretoria, Gauteng. This is to ensure a cross-section of participants were selected as advocated by [45].

The group session began with a standard introduction and explanation of the purpose of the research. The participants were taught on 'How rockets are launched' and later asked to give a diagrammatic representation of the topic. After the first image was produced, learners were exposed to knowledge visualisation principles (as stated in Table 1) and were required to apply this principles to the initial image produced. This resulted in some learners modifying the old image while others produced a new image. The two images produced by each learner was then compared and evaluated based on the given knowledge visualisation principles. Quantitative analysis was conducted on knowledge visualisation principles by comparing the level of compliance before and after being exposed to these principles while qualitative analysis was carried out on both knowledge visualisation principles that were not measured and general observations during the session.

\subsection{Results}

Table 2 shows the percentage level of compliance by learners before and after they were taught on knowledge visualisation principles. The analysis was carried out on the measurable knowledge visualisation principles.

\subsection{Analysis}

Fig. 1 shows the percentage change in compliance of learners after being briefed on what knowledge visualization entails.

While some learners felt the need to produce a completely new visualisation that will accommodate the guidelines, others were able to edit their initial diagram. Overall, only few did 
Table 2: Percentage level of compliancy by learners before and after the brief on knowledge visualisation principles

\begin{tabular}{|c|c|c|c|c|c|c|c|c|c|c|c|c|c|c|c|c|c|c|c|c|c|c|}
\hline & \multicolumn{2}{|c|}{ Know your data } & \multicolumn{2}{|c|}{$\begin{array}{c}\text { Abstract } \\
\text { knowledge }\end{array}$} & \multicolumn{2}{|c|}{ Clarity } & \multicolumn{2}{|c|}{$\begin{array}{c}\text { Avoid } \\
\text { decoration }\end{array}$} & \multicolumn{2}{|c|}{$\begin{array}{l}\text { Use of natural } \\
\text { representation }\end{array}$} & \multicolumn{2}{|c|}{$\begin{array}{c}\text { Easy to } \\
\text { understand }\end{array}$} & \multicolumn{2}{|c|}{ Simplicity } & \multicolumn{2}{|c|}{ Use of colours } & \multicolumn{2}{|c|}{$\begin{array}{c}\text { Clear } \\
\text { boundaries }\end{array}$} & \multicolumn{2}{|c|}{ Legend } & \multicolumn{2}{|c|}{$\begin{array}{c}\text { Relationship } \\
\text { between } \\
\text { concepts shown }\end{array}$} \\
\hline & Before & After & Before & After & Before & After & Before & After & Before & After & Before & After & Before & After & Before & After & Before & After & Before & After & Before & After \\
\hline Yes & $22 \%$ & $94 \%$ & $72 \%$ & $89 \%$ & $78 \%$ & $100 \%$ & $89 \%$ & $94 \%$ & $61 \%$ & $56 \%$ & $17 \%$ & $94 \%$ & $89 \%$ & $100 \%$ & $11 \%$ & $39 \%$ & $11 \%$ & $44 \%$ & $0 \%$ & $44 \%$ & $61 \%$ & $94 \%$ \\
\hline No & $78 \%$ & $6 \%$ & $28 \%$ & $11 \%$ & $22 \%$ & $0 \%$ & $11 \%$ & $6 \%$ & $39 \%$ & $44 \%$ & $83 \%$ & $6 \%$ & $11 \%$ & $0 \%$ & $89 \%$ & $61 \%$ & $89 \%$ & $56 \%$ & $100 \%$ & $56 \%$ & $39 \%$ & $6 \%$ \\
\hline $\begin{array}{l}\% \text { increase in } \\
\text { compliance }\end{array}$ & \multicolumn{2}{|c|}{$72 \%$} & \multicolumn{2}{|c|}{$17 \%$} & \multicolumn{2}{|c|}{$22 \%$} & \multicolumn{2}{|c|}{$5 \%$} & \multicolumn{2}{|c|}{$-5 \%$} & \multicolumn{2}{|c|}{$77 \%$} & \multicolumn{2}{|c|}{$11 \%$} & \multicolumn{2}{|c|}{$28 \%$} & \multicolumn{2}{|c|}{$33 \%$} & \multicolumn{2}{|c|}{$44 \%$} & \multicolumn{2}{|c|}{$33 \%$} \\
\hline
\end{tabular}

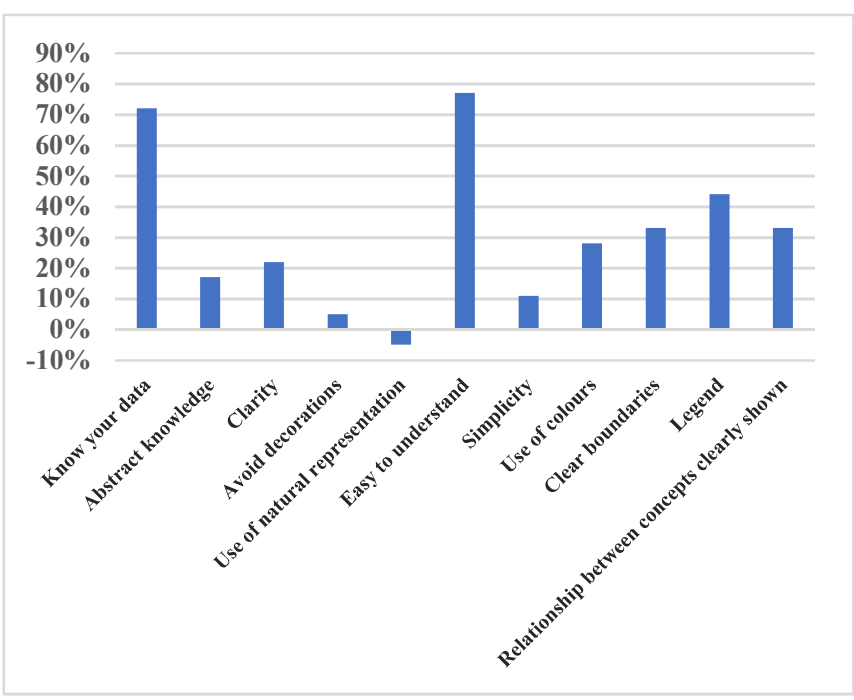

Fig. 1: Percentage increase/decrease in compliance

not feel the need to make any adjustment to their diagrams.

The before and after images of each learner was compared and below is a summary of the observations.

\subsection{Findings}

Fig. 2 below show samples of some of the learners' visualisation before and after the brief on knowledge visualisation principles. The figure reflects some of the observations noted in subsequent sections. In the first example, more information is added in terms of content and structure (relations between components). In the second example, a title is added to the visualisation (easy to understand), together with a description of the symbols used (legend). The former considered a visualisation to be a central picture and the guidelines led to fragmentation. Obviously, that should not be at the expense of coherence so the unintended consequences of the guidelines need to be monitored throughout.

\subsection{Guidelines with noticeable influence on final} diagram

The following guidelines had a percentage influence on the final diagram ranging from $22 \%$ to $77 \%$ compliancy level: Know your data, Clarity, Easy to understand, Use of colours, Clear boundaries, Legend and Relationship between concepts clearly shown.

None of the learners added a legend in their initial visualisation. However, after the brief, $44 \%$ of the learners felt there was a need to give a meaningful explanation of the symbols used by adding a legend thereby aiding other knowledge visualisation principles.

Clear boundaries may be subject to the context of the topic being visualized i.e. it is less applicable when the visualisation is within the same domain.

The high level of compliance for the 'Easy to understand' guideline was influenced by the compliancy of other guidelines, indicating inter-guideline dependencies.

Although there was a percentage increase of $28 \%$ for the use of colours after the brief on knowledge visualisation principles, a number of participants were cautious in the way they implemented this principle so as to avoid compromising other principles such as 'avoid decorations'. For others, it was a quick way to implement the principle on 'clear boundaries'.

5.2 Guidelines with little or negligible influence in final diagrams

The guidelines: Abstract knowledge, Avoid decorations and Simplicity had compliancy levels ranging from $5 \%$ to $17 \%$.

From observation, $89 \%$ of the learners created a visualisation void of symbols whose meaning was not related to the content of the study.

Thus, the 'avoid decorations' principle did not make a substantial difference in the final images produced by the learners, especially after a legend was added to give meaning to symbols used. Also, the 'abstract knowledge' and 'simplicity' principles did not create much impact on the final images produced by learners.

For the former, this may be because of time constraint thus making learners include the most important point before the time for the test elapse while the nature of the topic being visualized may account for the latter.

5.3 Guideline with a drop in the percentage of compliance (Use of natural representation)

Learners in the research group did have personal preferences when using visualisation to represent knowledge. While most agree that using images to represent and transfer knowledge is a field they are willing to explore, others have expressed their reservations on the use of images to represent their knowledge. The latter believe that to implement knowledge visualisation, you must be artistically inclined. In view of these, there was a 5\% drop in the compliance level for 


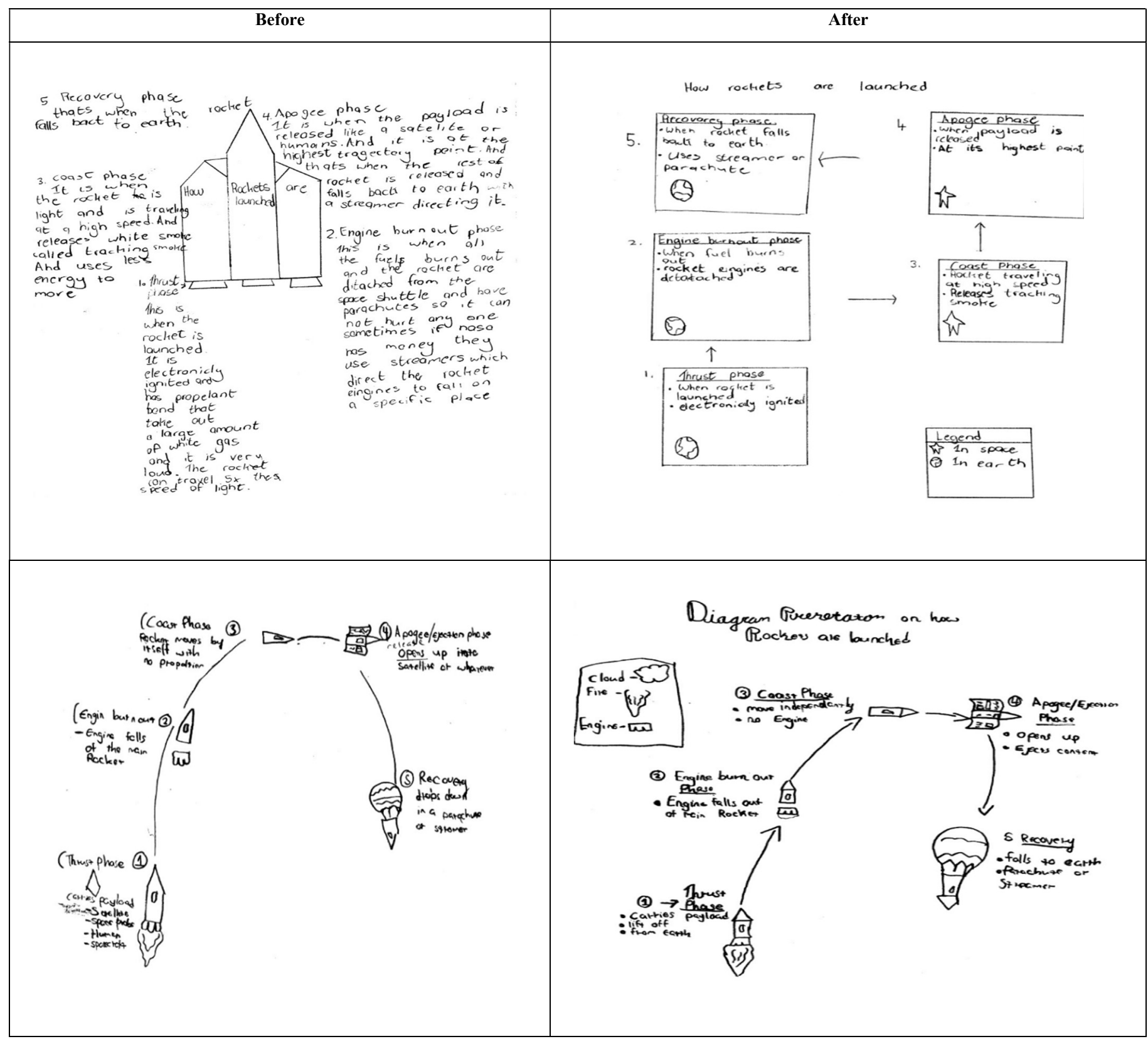

Fig. 2. Samples of learners' visualisation before and after knowledge visualisation guidelines brief

participants who expressed their concern that their representation of the real world may be violating another principle i.e. avoid decorations. Furthermore, it is argued that the use of natural representation can be subjected to the designer's background. For example, the use of fire to represent volcanic eruption in the geographical field may be seen as heat in the chemical field.

\subsection{Guidelines that may have been difficult for the focus} group to understand and implement

Learners found the 'Motivate audience' guideline difficult to implement. Some of the questions raised were: whether to make the images produced very attractive, add a motivational paragraph in form of an introduction to the diagram or produce images that speak to a particular audience. However, the learners argued that implementing these suggestions may compromise some of the learnt principles such as abstracting the data, avoid decorations etc.

\subsection{Guidelines that were difficult to measure}

The guidelines: Know your audience; Consistency; Motivate audience; and Dual coding were explained to the learners but the visualisation were not evaluated thereof.

\subsection{Guidelines that were easier to implement electronically than on paper}

The execution of the 'Present overview and detail' principle was more easily implemented by most learners electronically 
than on paper. Devices used for visualisation e.g. desktop computers, laptops etc. usually have inbuilt technologies that makes it possible to zoom in on a particular section of an image, accounting for this. However, it is important to note the issue of usability in e-learning where there is the need to first know how to use the application [51].

\subsection{The execution/effect of one guideline on another}

The execution of some guidelines increased the conformity of others. In essence, some guidelines were observed to be interrelated as the execution of one gives credit to the implementation of another. Examples are:

- $\quad$ Legend (clarity, easy to understand, consistency)

- $\quad$ Easy to understand (simplicity, abstract the data, avoid decorations)

- Avoid decoration (Legend)

6.0 Factors that may have influenced learners' conformity to knowledge visualisation guidelines before/after brief

Various factors may have influenced learners' compliance with knowledge visualisation guidelines either before or after the brief. This includes aspects such as providing a rubric for the diagram, information overload, and the time constraint. In addition, knowledge-based visualisation applications work only on specific domains/tasks and thus cannot be generalized [18, $37,46,47,48]$. There is also the risk of possible distortion of reality through misinterpretations [48]. The diversity in learners literacy skills and learning styles also affect how knowledge visualisation can be used for teaching and learning [49]. The lack of automatization in the process of creating knowledge visualisation [18] and the constraints of the mobile technology platform on which knowledge visualisation can be implemented e.g. connectivity, power, size of screen, memory etc [13] may have played a role. The high tendency to provide too much information to learners during teaching and learning may also have led to disorientation and cognitive overload [50].

\subsection{Conclusion and Future work}

This paper discussed how knowledge visualisation principles could provide support in improving knowledge transfer amongst high school learners. The findings indicate that most of the principles considered in this study provided various degrees of impact on the images produced by learners. While some made significant impact, others' impact could be considered negligible. This allows prioritization of the knowledge visualisation principles, for the context of high school learners.

Acknowledgements: This work is based on the research supported by the South African Research Chairs Initiative of the Department of Science and Technology and National Research Foundation of South Africa (Grant No 98564)

\section{REFERENCES}

Y. Zhang, X. He, J. Xie, and Z. Wang, "Study on the knowledge visualization and creation supported Kmap platform," in $1 s t$ International Workshop on Knowledge Discovery and Data Mining, WKDD, 2008, pp. 154-159.
Knowledge Visualization on Externalizing Tacit Knowledge," in Proceeding of the International Conference on Advanced Science Engineering and Information Technology, 2011, pp. 124-128.

[3] E. Strakhovich, "Ontological Engineering in Education: Tools for Knowledge Transfer and Knowledge Assessment," in International Conference on Advanced Learning Technologies, 2014, pp. 714-715.

J. VanBiljon and K. Renaud, "Facilitating knowledge visualisation as communication and knowledge transfer mechanism in postgraduate learning," in International Conference on Mobile and Contextual Learning, 2015, pp. 156-171.

[5] S. Wright, "Deep Learning Isn't about Technology," 2012. [Online]. Available: http://plpnetwork.com/2012/09/24/deeper-learningtechnology/. [Accessed: 04-Oct-2016].

[6] L. Manovich, "What is visualization?," J. Initiat. Digit. Humanit. Media, Cult., vol. 2, no. 1, pp. 1-32, 2010.

T. Munzner, "Visualization," in Fundamentals of Graphics, 2009, pp. 675-707.

M. Chen et al., "Data, Information, and Knowledge in Visualization," Comput. Graph. Appl. IEEE, vol. 29, no. 1, pp. 12-19, 2009.

Z. Yusoff, S. A. Katmon, M. N. Ahmad, and S. H. M. Miswan, "Visual representation: Enhancing students's learning engagement through knowledge visualization," in International Conference on Informatics and Creative Multimedia, 2013, pp. 242-247.

[10] R. A. Burkhard, "Learning from architects:the difference between knowledge visualization and information visualization," in Information Visualisation, 2004., 2004, pp. 519-524.

[11] S. Bertschi et al., "What is knowledge visualization? Perspectives on an emerging discipline," in Proceedings of the International Conference on Information Visualisation, 2011, pp. 329-336.

[12] M. J. Eppler, "What is an effective knowledge visualization? Insights from a review of seminal concepts," in Proceedings of the International Conference on information Visualisation, 2011, pp. 312.

[13] J. Van Biljon and K. Renaud, "Do Visualizations Ease Dissertation Assessment?," in Proceedings of the 44th Annual Southern African Computer Lecturers Association 2015 (SACLA 2015), 2015, pp. 177185.

[14] C. Okoli and K. Schabram, "Protocol for a Systematic Literature Review of Research on the Wikipedia," Work. Pap. Inf. Syst., vol. 9, no. $65,2009$.

[15] C. Atkins and G. Louw, "Reclaiming Knowledge: A Case for Evidence-Based Information Systems," in Proceedings of the European Conference on Information Systems, 2000, p. Paper 28.

[16] B. J. Oates, H. M. Edwards, and D. W. Wainwright, "A ModelDriven Method for the Systematic Literature Review of Qualitative Empirical Research,” in ICIS 2012 Proceedings, 2012, pp. 1-18.

[17] W. Aigner, A. Rind, and S. Hoffmann, "Comparative Evaluation of an Interactive Time-Series Visualization that Combines Quantitative Data with Qualitative Abstractions," Comput. Graph. Forum, vol. 31, no. 3, pp. 995-1004, 2012.

[18] N. Scarpato, P. Maria, and T. Pazienza, "Knowledge-based visualization systems," University of Rome Tor Vergata, 2012.

[19] S. Kumar, "A Review of Recent Trends and Issues in Visualization," 
Int. J. Comput. Sci. Eng., vol. 8, no. 3, pp. 41-54, 2016.

[20] J. Heer, B. Shneiderman, and C. Park, "A taxonomy of tools that support the fluent and flexible use of visualizations," ACM Queue, vol. 10 , no. 2 , pp. 1-26, 2012.

[21] J. Mengis and M. J. Eppler, "Visualizing instead of Overloading: Exploring the Promise and Problems of Visual Communication to Reduce Information Overload," in Information Overload: An International Challenge for Professional Engineers and Technical Communicators, 2012, pp. 203-229.

[22] J. C. Roberts, "State of the Art: Coordinated \& Multiple Views in Exploratory Visualization," in Fifth International Conference on Coordinated and Multiple Views in Exploratory Visualization, 2007, pp. 61-71.

[23] S. Burigat and L. Chittaro, "On the Effectiveness of Overview + Detail Visualization on Mobile Devices," IEEE Trans. Vis. Comput. Graph., vol. 17, no. 2, pp. 1-18, 2013.

[24] C. Ware, Information visualization: perception for design, Third. Elsevier, 2012.

[25] S. Bresciani and M. J. Eppler, "The Pitfalls of Visual Representations," SAGE Open, vol. 5, no. 4, pp. 1-14, 2015.

[26] A. Figueiras, "How to Tell Stories Using Visualization," in 8th International Conference on Information Visualisation, 2014, pp. 18-26.

[27] Y. Zhou, L. Yin, and L. Wang, "A research for the classification of knowledge visualization," in International Conference on Electrical and Control Engineering, 2011, pp. 6235-6238.

[28] T. Gavrilova, I. Leshcheva, and E. Strakhovich, "Gestalt principles of creating learning business ontologies for knowledge codification," Knowl. Manag. Res. Pract., vol. 13, no. 4, pp. 418-428, 2015.

[29] K. L. Ma, I. Liao, J. Frazier, H. Hauser, and H. N. Kostis, "Scientific storytelling using visualization," IEEE Comput. Graph. Appl., vol. 32, no. 1, pp. 12-19, 2012.

[30] R. Meyer, "Knowledge Visualization," Trends Inf. Vis., vol. 23, pp. 63-84, 2010.

[31] C. Ware, "Chapter Eleven - Visual Thinking Processes," in Interactive Technologies, 2013, pp. 375-423.

[32] S. Haroz, R. Kosara, and S. L. Franconeri, "ISOTYPE Visualization - Working Memory, Performance, and Engagement with Pictographs," in Proceedings of the 33rd Annual ACM Conference on Human Factors in Computing Systems - CHI '15, 2015, pp. 11911200 .

[33] M. A. Borkin et al., "Beyond Memorability: Visualization Recognition and Recall," IEEE Trans. Vis. Comput. Graph., vol. 22, no. 1, pp. 519-528, 2016.

[34] A. Hall and K. Virrantaus, "Visualizing the workings of agent-based models: Diagrams as a tool for communication and knowledge acquisition,” Comput. Environ. Urban Syst., vol. 58, pp. 1-11, 2016.

[35] Q. Zhi and M. Su, "Enhance Collaborative Learning by Visualizing Process of Knowledge Building with Padlet," in International Conference of Educational Innovation through Technology (EITT), 2015, vol. 1, pp. 221-225.

[36] J. Hullman and N. Diakopoulos, "Visualization rhetoric: Framing effects in narrative visualization," IEEE Trans. Vis. Comput. Graph., vol. 17, no. 12, pp. 2231-2240, 2011.

[37] M. Wang, J. Peng, B. Cheng, H. Zhou, and J. Liu, "Knowledge Visualization for Self-Regulated Learning," Educ. Technol. Soc., vol. 14, no. 3, pp. 28-42, 2011.

[38] R. C. Green, L. Wang, and M. Alam, "The impact of plug-in hybrid electric vehicles on distribution networks: A review and outlook," Renew. Sustain. Energy Rev., vol. 15, no. 1, pp. 544-553, Jan. 2011.

[39] X. Bai, D. White, and D. Sundaram, "Contextual Adaptive Knowledge Visualization Environments.," Electron. J. Knowl. Manag., vol. 10, no. 1, pp. 1-14, 2012.

[40] S. Bresciani, J. Ge, and Y. Niu, "The Effect of Visual Mapping on Attitude toward Organizational Strategy: Scale Development and Application in Europe and China," in International Conference on Communication, Media, Technology and Design, 2014, vol. 2, no. 4, pp. 275-283.

[41] F. T. Marchese and E. Banissi, Knowledge visualization currents: From text to art to culture. Springer Science \& Business Media, 2012.

[42] C. Ware, "Chapter Nine - Images, Narrative, and Gestures for Explanation," in Information Visualization, 2013, pp. 325-343.

[43] N. Diakopoulos, F. Kivran-Swaine, and M. Naaman, "Playable data: characterizing the design space of game-y infographics," in Proceedings of the 2011 annual conference on Human factors in computing systems, 2011, pp. 1717-1726.

[44] B. J. Oates, Researching Information Systems and Computing. Sage Publications, 2006.

[45] R. a. Krueger and M. a. Casey, "Participants in a Focus Group," in Focus Groups: A Practical Guide for Applied Research, 2009, pp. 63-84.

[46] N. Sun, K. Li, and X. Zhu, "Action Research on Visualization Learning of Mathematical Concepts Under Personalized Education Idea: Take Learning of Geometrical Concepts of Elementary Math for Example," in International Conference on Blending Learning, 2016, pp. 348-359.

[47] C. Evert, "A Model Using Technological Support for Tutors in Practical Computing Sessions," Nelson Mandela Metropolitan University, 2015.

[48] M. J. Eppler and R. A. Burkhard, "Knowledge Visualization Towards a New Discipline and its Fields of Application," ICA Work. Pap., 2004

[49] H. J. Lin and L. H. Chen, "Discovering learning pattern in different cognitive style of learners," Proc. - 3rd Int. Conf. Converg. Hybrid Inf. Technol. ICCIT 2008, vol. 2, no. 168, pp. 268-273, 2008.

[50] X. Aidi, "Cognitive overload and its countermeasures from the angle of information processing," in 3rd International Symposium on Intelligent Information Technology Application, 2009, vol. 1, pp. 391-394.

[51] S. Ssemugabi and R. de Villiers, "Effectiveness of heuristic evaluation in usability evaluation of elearning applications in higher educ," South African Comput. J., vol. 45, no. 45, pp. 26-39, 2010. 